\title{
Crypts in Asymmetric Fission in Endoscopic Biopsies from Swedish Patients With Inflammatory Bowel Disease
}

\author{
CARLOS A. RUBIO ${ }^{1}$ and PETER T. SCHMIDT ${ }^{2}$ \\ ${ }^{1}$ Gastrointestinal Research Laboratory, Department of Pathology, \\ Karolinska Institute and University Hospital, Stockholm, Sweden; \\ ${ }^{2}$ Department of Medicine (Solna), Karolinska Institute and Ersta Hospital, Stockholm, Sweden
}

\begin{abstract}
Background/Aim: We previously found crypts in symmetric fission (CSF) and in asymmetric fission (CAF) in colectomy-specimens with ulcerative colitis. We now analyzed CSF and CAF (CSAF) in biopsies from 80 patients with inflammatory bowel disease (IBD) without dysplasia or carcinoma. Patients and Methods: One unselected doublebiopsy from affected endoscopic areas was investigated in the 80 cases. Results: A total of 353 crypts in fission were found. The median number of CAF/biopsy was 3.7 and for CSF/biopsy, 0.7 ( $p<0.00001)$. Conclusion: CSAF often occur in unselected biopsies from patients with IBD. Whereas the increased frequency of CSF might mirror a compensatory mechanism of crypt production in areas occupied by inflammation, CAF reflects a pathological aberration of cryptogenesis, probably generated by somatic mutations. The biological significance of CAF in IBD without dysplasia or carcinoma, deserves to be further investigated.
\end{abstract}

Besides the high number of inflammatory cells, mainly in the lamina propria, histologic sections in ulcerative colitis (UC) typically exhibit crypts with architectural distortions. The concept of crypts with architectural distortions has received various trivial names in the literature, such as alteration in crypt configuration (1), architectural aberrations (2), distortion of the crypts (3), crypt architectural irregularities (4), corrupted colon crypts (5), and crypts with architecture abnormalities (6), to

This article is freely accessible online.

Correspondence to: Carlos A. Rubio, MD, Ph.D., Gastrointestinal Pathology Research Laboratory, Department of Pathology, Karolinska Institute and University Hospital, 17176, Stockholm, Sweden. Tel: +46 851774527, Fax: +46 851774524, e-mail: Carlos.Rubio@ki.se

Key Words: Colon biopsies, inflammatory bowel disease, crypts, asymmetric fission. name some. Crypts with architectural distortions in UC includes crypt branching. In 1972, Basil Morson reported crypt budding and crypt branching in rectal biopsies from patients with UC (7). In 1986, Cheng, Bjerknes, and Gardiner (8) found high percentages of branching crypts in diseased colonic epithelium from patients with UC, Crohn's disease, and multiple polyposis; it was concluded that branching crypts represented a stage in the process of crypt replication (8). In 1991, Seldenrijk et al. (9) defined crypt branching in UC and Crohn disease, when $\geq 2$ branched crypts were found in well oriented biopsies, emphasizing that crypt branching was easily recognized when seen in the vertical plane, but not in the horizontal plane, as crypts often displayed acinar profiles (9). In 2002, Washington et al. (10) defined diffuse mucosal architectural distortion, as obvious irregularities in crypt shape, spacing, and size, with loss of crypt parallelism involving the entire biopsy fragment, and in 2004, Glickman et al. (11) listed crypt branching among architectural features of chronicity in UC. More recently, DeRoche et al. (12) registered crypts with architectural distortion, typified by crypt shortening (i.e., presence of space between the bottom of the crypts and the upper edge of the muscularis mucosae) and crypt branching. According to Gajendram et al. (13), the diagnosis of UC is made in $75 \%$ of the cases when two or three of the four following microscopic changes were present: severe crypt architectural distortion, severely decreased crypt density, irregular mucosal surface, and heavy diffuse transmucosal inflammation without genuine granuloma. In the aforementioned reports, the descriptions and illustrations of crypts with architectural distortions -including crypt branching- were based on well-oriented sections, at right angles to the muscularis mucosae.

Sections from rectal biopsies typically show crypts cut in a horizontal plane. In 1982, we assessed the frequency of cross-cut crypts in rectal biopsies from patients with UC (14). The transected ring-shaped crypts revealed architectural distortions and in cases with UC in remission, twin-crypt dichotomy (15). The latter, called the 'back-to-back sign, was easily recognized at the point of crypt bifurcation; it was 

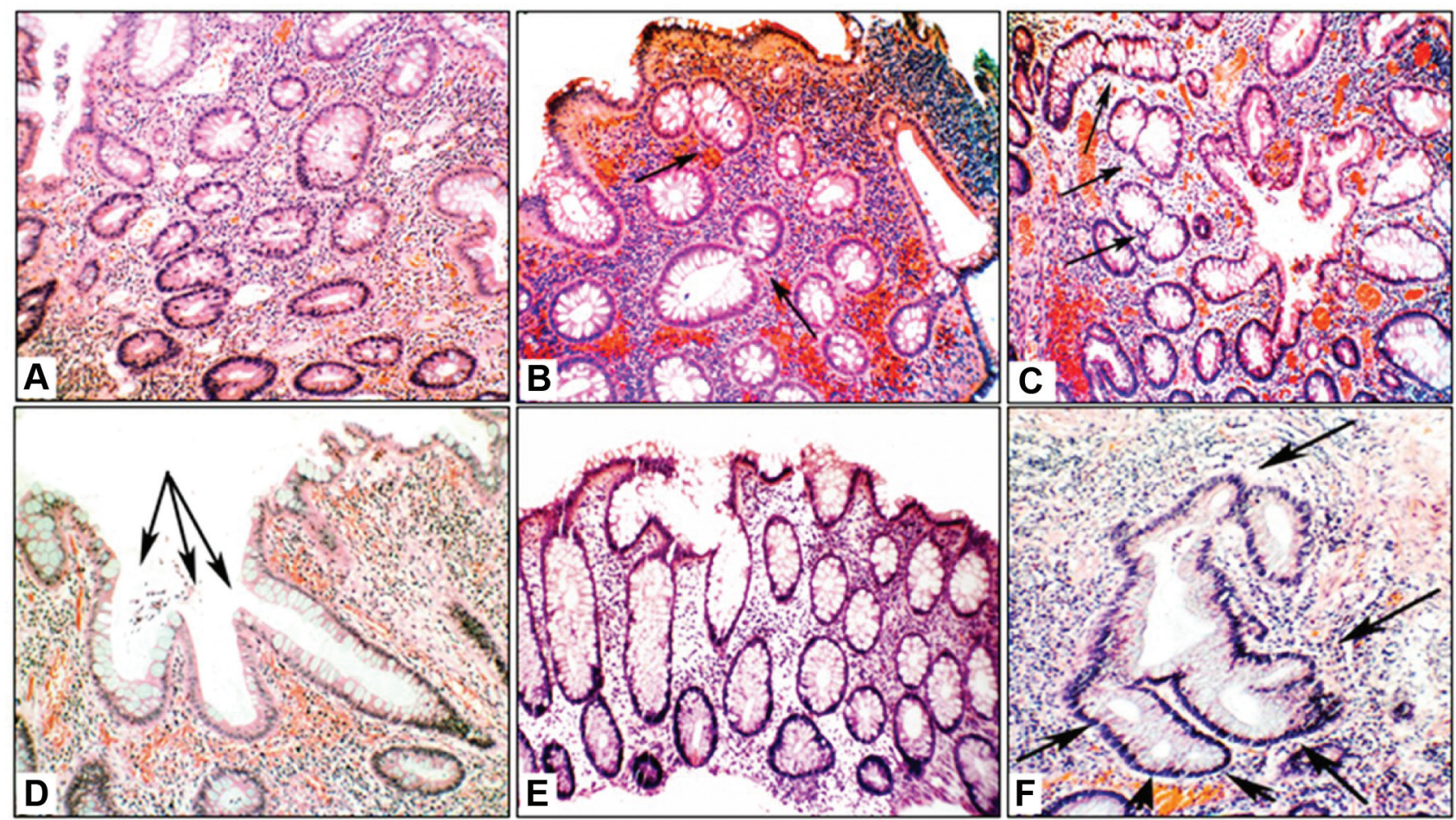

Figure 1. Colon crypts with architectural distortions in inflammatory bowel disease. A: Cross-cut crypts in disarray showing different diameters separated by unequal amounts of lamina propria showing chronic inflammation $(H \& E$ original $\times 10)$. B: Cross-cut crypts with architectural distortions. Note one crypt in symmetric fission (upper arrow), and another crypt in asymmetric fission (lower arrow) (H\&E original $\times 10)$. C: Cross-cut crypts with architectural distortions including crypts in asymmetric fission (upper two arrows) and in symmetric fission (lowest arrow) $(H \& E$ original $\times 10)$. D: Upright crypt with three-foiled asymmetric fission, at arrows $(H \& E$ original $\times 20)$. E: Upright crypt in asymmetric fission $(H \& E$ original $\times 10)$. F: Cross-cut crypt in asymmetric fission surrounded by lamina propria with chronic inflammation. Note the different size in the seven crypt-lumina $(H \&$ E original $\times 20)$.

considered to represent crypts in fission (15). Subsequently, while studying sections cut in a vertical plane, we found at the edge of mucosal ulcers in three colectomy specimens with UC, 70 crypts with architectural distortions; 30 (43\%) of those were in asymmetric fission (16). In a more recent study of seven colectomy-specimens from patients with UC, having sections cut in a vertical plane, albeit with random cross-cut-crypts areas, we found crypts with architectural distortions, including 3,586 crypts in fission; of those, 2,930 $(82 \%)$ were in asymmetric fission (17). From these findings, it was deduced that crypts in asymmetric fission often occur in specimens from colectomy specimens with UC.

Endoscopic biopsies are often cross-cut in a horizontal (tangential) plane during processing and the resulting sections mainly reveal cross-cut crypt-rings. Against that background, the pertinent question was: Could cross-cut sections from endoscopic biopsies in patients with IBD include among crypts with architectural distortions, crypts in asymmetric fission? To answer that question, we reexamined a cohort of surveillance endoscopic biopsies from patients with UC and Crohn colitis.

\section{Patients and Methods}

The material includes endoscopic biopsies from 80 patients with IBD without dysplasia or carcinoma (40 with UC and 40 with Crohn's colitis), under surveillance. Two endoscopic biopsies were taken from each of 10 different colon-levels. Histological sections (4 $\mu \mathrm{m}$ thick) were stained with hematoxylin and eosin (H\&E). Each slide had 10 sections, five for each biopsy. From endoscopically affected areas, one unselected double-biopsy was used in this study. Sections were scrutinized in a standard Nikon light microscope (Surbiton, UK) carrying $\times 10$ ocular lenses and a $\times 10$ Plan Apo objective (aperture 0.45 ). All symmetric and asymmetric crypts in fission found in the sections from the 80 cases, were recorded.

\section{Definitions}

Architectural crypt distortions in biopsies from patients with IBD. Crypts with architectural distortions were regarded as those varying in size, often with irregular shapes, separated by dissimilar amounts of lamina propria, often with chronic inflammation. Crypts with architectural distortions included crypts in fission.

Crypts in symmetric fission in biopsies from patients with IBD. In transected (cut-across) crypts. Colonic biopsies often revealed transected (cut across), back-to-back, ring-shaped, symmetric twin 

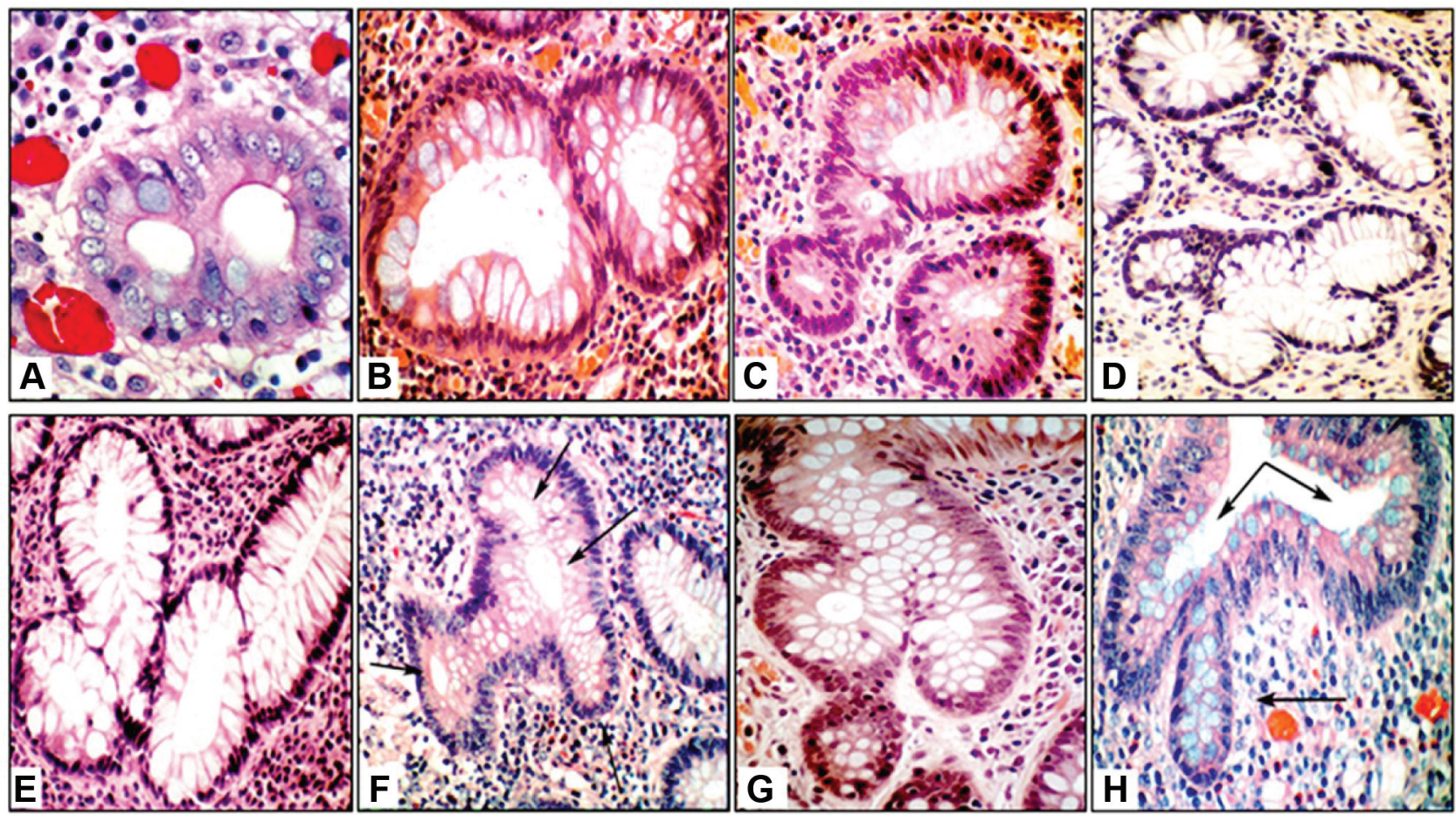

Figure 2. Colon crypts in symmetric and in asymmetric fission in inflammatory bowel disease. A: Cross-cut back-to-back, ring-shaped, symmetric twin crypts of similar diameter, separated from each other by a thin layer of epithelial cells (H\&E original $\times 40)$, B: Cross-cut crypt in asymmetric fission, separated from each other by a thin layer of epithelial cells (H\&E original $\times 40), C$ : Cross-cut crypt in asymmetric fission portraying three lumina of different size ( $H \& E$ original $\times 40), D, E F$ : Various phenotypes of cross-cut crypts in asymmetric fission $(H \& E$ original $\times 20)$, $G, H$ : Close view of upright crypts in asymmetric fission ( $H \& E$ original $\times 40)$.

crypts of similar diameter, separated from each other either by a thin layer of epithelial cells or a rim of lamina propria (7). In similarity with rectal biopsies (15), crypts with these characteristics in the colon, were referred to as the back-to-back sign (Figures 1B and $2 \mathrm{~A}$ ), and regarded to be in symmetric fission.

In vertically-oriented crypts. In well oriented sections, two identical colonic crypts, sharing a single luminal opening on top.

Crypts in asymmetric fission in biopsies from patients with IBD. In transected (cut across) crypts. Two or more back-to-back "ringshaped" crypts varying in diameter and/or shape, joined by a thin epithelial rim (Figure 1B, C, F, Figure 2B-F and Figure 3).

In vertically-oriented crypts. In well oriented sections, two or more crypts of different diameters, lengths and/or shapes, sharing a single luminal opening on top (Figure 1D, E and Figure 2G, H).

Ethical approval. The Regional Ethical Review Board in Stockholm approved this study (EPM dnr 2020-01634). Since the study is retrospective and the sections were coded and studied anonymized, the Regional Ethical Review Board in Stockholm approved that informed consent from the patients was not required.

Statistical analysis. The non-parametric Mann-Whitney $U$ two-tail test was applied to compare difference between groups, using the Social Science Statistics. Statistical significance was defined as $p<0.05$.

\section{Results}

Number of crypts in asymmetric and in symmetric fission in biopsies from patients with IBD. Out of the 353 crypts in fission in the 80 cases with IBD in Table I, 296 (83.9\%) were asymmetric and the remaining $57(16.1 \%)$ symmetric. The median number of crypts in asymmetric fission/biopsy was 3.7 (range=0-7), and the median number of crypts in symmetric fission, 0.7 (range $=0-2)$, respectively $(p<0.00001)$.

In UC, out of 196 crypts in fission, 166 (84.7\%) were in asymmetric fission. The median number of crypts in asymmetric fission per biopsy was 4.2 (range=0-7). In Crohn colitis, out of the 157 crypts in fission, 130 (82.8\%) were in asymmetric fission. The median number of crypts in asymmetric fission per biopsy was 3.3 (range=0-7). The median number of crypts in asymmetric fission in UC and in Crohn colitis was non-significant ( $p=0.00634)$.

Crypts in asymmetric fission exhibiting abscesses were often found in areas with active mucosal inflammation in biopsies from patients with IBD (Figure 3).

Number of transected crypts and vertical crypts in fission in biopsies from patients with IBD. Out of the 296 asymmetric 

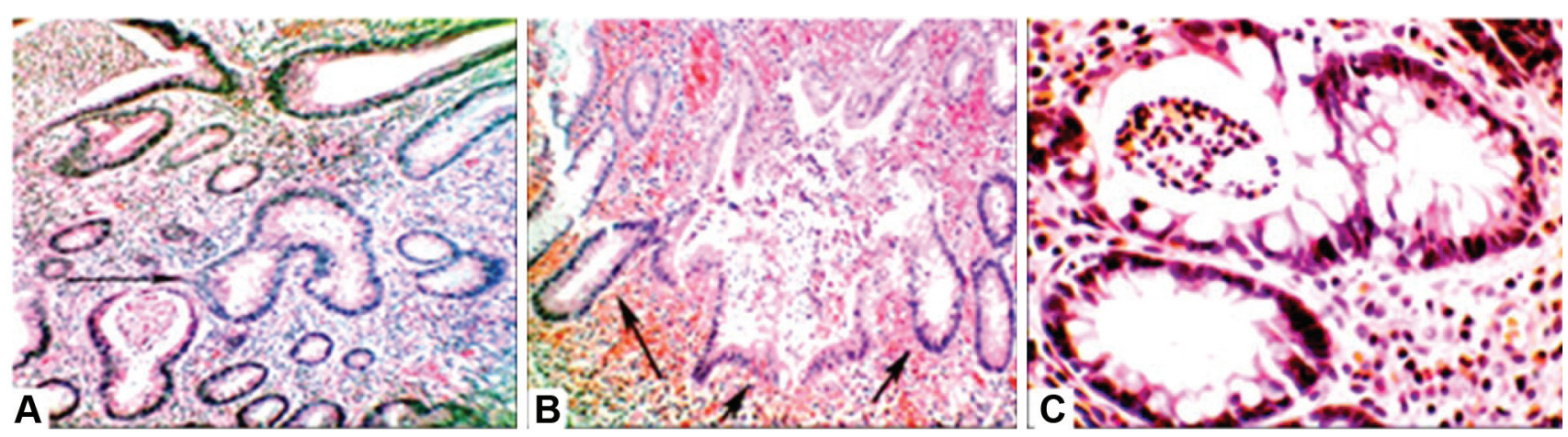

Figure 3. Colon crypts in asymmetric fission with crypt-abscesses. A: Cross-cut crypts with architectural distortions, showing several crypt-abscesses, one in a crypt in asymmetric fission (arrow) (H\&E original $\times 10)$. B: Cross-cut crypt in asymmetric fission, at arrows, with abscess (H\&E original $\times 10)$. C: Closer view of a crypt in asymmetric fission, with abscess ( $H \& E$ original $\times 40)$.

Table I. The number of colon crypts in asymmetric fission and in symmetric fission in endoscopic biopsies from 40 patients with ulcerative colitis and in 40 with Crohn colitis.

\begin{tabular}{|c|c|c|c|c|c|c|c|}
\hline & \multicolumn{3}{|c|}{$\begin{array}{l}\text { No. of crypts in asymmetric and } \\
\text { in symmetric fission } \\
\text { in } 40 \text { endoscopic biopsies } \\
\text { in patients with ulcerative colitis }\end{array}$} & \multicolumn{3}{|c|}{$\begin{array}{l}\text { No. of crypts in asymmetric and } \\
\text { in symmetric fission } \\
\text { in } 40 \text { endoscopic biopsies } \\
\text { in patients with Crohn colitis }\end{array}$} & \multirow[t]{2}{*}{ Total } \\
\hline & $\begin{array}{l}\text { No. of asymmetric } \\
\text { crypt in fission }\end{array}$ & $\begin{array}{l}\text { No. of symmetric } \\
\text { crypt in fission }\end{array}$ & Total & $\begin{array}{l}\text { No. of asymmetric } \\
\text { crypt in fission }\end{array}$ & $\begin{array}{l}\text { No. of symmetric } \\
\text { crypt in fission }\end{array}$ & Total & \\
\hline Total & 166 & 30 & 196 & 130 & 27 & 157 & 353 \\
\hline Mean & 3.8 & 0.8 & 4.9 & 3.3 & 0.7 & 3.9 & 4.4 \\
\hline Range & $0-7$ & $0-2$ & $1-7$ & $0-7$ & $0-2$ & $1-7$ & $0-7$ \\
\hline
\end{tabular}

crypts in fission, 235 (79.4\%) had been transected (crosscut), and the remaining $61(20.6 \%)$ both cross-cut and vertically cut $(p<0.00001)$.

\section{Discussion}

The present findings showed that crypts in symmetric and asymmetric fission are often found in unselected biopsies obtained from endoscopically affected areas in patients with UC and Crohn colitis under surveillance. The majority of the crypts in fission were in asymmetric fission (85\% in UC and $83 \%$ in Crohn colitis, respectively). The relatively high frequency of crypts in fission in colon biopsies in IBD found here, contrasts with the absence of crypts in asymmetric fission and the rare occurrence of crypts in symmetric fission in the normal colon mucosa of adults (18-20). Furthermore, Goldstein and Ahmad (21) found in sigmoid colon specimens removed for protracted diverticulitis $(n=100)$ or adenocarcinoma that also exhibited diverticulitis $(\mathrm{n}=53)$, that the colonic crypts retained their normal shape, despite ongoing chronic inflammation. No crypts with architectural distortions were found (21), strongly suggesting that ongoing chronic inflammation per se does not encourage the development of crypts with architectural distortions, including crypt branching. Consequently, causes other than chronic inflammation might be responsible for the evolution of crypts with architectural distortions, including crypts in symmetric and in asymmetric fission in IBD.

Forty years ago, we explored several histologic variables in transected (cut across) crypts, present in rectal biopsies from 72 rheumatic patients without gastrointestinal symptoms, having histologically normal rectal mucosa (22). The variables in ten consecutive transversally cut glands were: crypts diameter (minor axis), the distance between glands, the number of glands using a $40 \times$ objective, and the number of nuclei in ten consecutive spaces of lamina propria between glands. The sum of the values in each variable in the control patients was considered the score describing the 
histological state of the normal rectal mucosa. In patients with UC, rectal biopsies showed higher scores due to wide variations in the aforementioned variables (14) and those in remission (15) revealed twin-crypts in fission. Similar variations can empirically be appreciated in colon biopsies from IBD patients (Figures 1 and 3).

The cell population in the crypts is coordinated by stem cells (23-25). The stem cell niche keeps the cell number in the crypts in balance. Wnt signaling controls apoptosis along the crypts, cell differentiation, and cell proliferation. High concentrations of Wnt are found at the bottom of the crypt (the stem cells domains) and low in the upper portion of the crypts (where differentiated cells reside). In contradistinction, APC concentration is high in the upper portion of the crypts and low at the bottom of the crypts $(26,27)$. Wnt signaling has been linked to crypt fission, being required for the production of colon crypts in infant rats and mice in vitro (28).

In later years, the notion of "branching" has attracted the attention of evolutionary biologists. Transdisciplinary literature searching, indicates that the antagonistic balance between noggin and bone morphogenetic protein 4 (BMP4) is necessary for feather branching (29). BMP4 stimulates rachis development and barb fusion, and noggin boosts rachis and barb branching. In another study, Harris et al. (30) studied the dynamics of morphogenesis molecules in embryonic feather buds and branching. Feather branching developed by activator-inhibitor interactions between one morphogenetic protein 2 (Bmp2) signaling in the basal epithelium of the feather germ and Sonic hedgehog (Shh). The integration of barb ridge morphogenesis triggered the development of feather structures. Thus, Yu et al. (29) and Harris et al. (30) identified the molecular signaling of branched structures, thereby demonstrating that branching feathers in birds is coordinated by several morphogenic molecules. Wnt signaling also regulates key events during morphogenesis and embryonic patterning $(29,30)$. In light of this transdisciplinary molecular knowledge, the question is: Could mutations in morphogenic molecules have contributed to the generation of morphogenic aberrations in crypts in symmetric fission, leading to asymmetric crypt formation in IBD?

Taking into account that the cause(s) responsible for the evolution of pathological aberrations of cryptogenesis in IBD remain elusive, the following questions seem pertinent: i) Could the mutagenic colon bacteria found in the colonic microenvironment in IBD (31-33) had set aflame the development of crypts in asymmetric fission?; ii) Could crypts with asymmetric fission had been generated by the IBD medication?

The presence of crypt-abscesses (Figure 3) appears not to be the cause for the formation of crypts in asymmetric fission, inasmuch as crypts in asymmetric fission were often found in mucosal domains without crypt-abscesses (Figures 1 and 2).
To characterize the process of clonal expansion in crypts with high-grade dysplasia in UC, Chen et al. (34) investigated dysplastic and non-dysplastic crypts within the same individual. Arbitrary primed (AR) and inter-simple sequence repeat PCR DNA fingerprint-mutation profiles of single crypts were compared with the mutational profiles from clusters of crypts and whole biopsies within the same individual. The authors (34) demonstrated that the mechanism of clonal expansion can occur through crypt fission, and that DNA alterations, initiated in a group of colonic crypts, may expand to adjacent crypts through crypt fission. Cheng et al. suggested that following continuous DNA mutations, the clonal expansion through crypt fission and clonal succession could initiate the development of inflammatory-associated high grade dysplasia (34). In summary, unselected endoscopic biopsies from affected areas in patients with UC and Crohn-colitis often exhibit crypts with architectural distortions, mostly crypts in asymmetric fission, but also in symmetric fission. The accruing of crypts in symmetric fission in IBD might be the result of a compensatory homeostatic mechanism of crypt production in mucosal areas previously occupied by inflammatory cells. However, crypts in asymmetric fission are pathological aberrations of cryptogenesis, most probably generated by unfolding somatic mutations. Whether there is any relationship between crypts with asymmetric fission without dysplasia in IBD and dysplastic crypts harboring committed mutations in UC $(35,36)$ and Crohn colitis $(37)$, remains to be explored.

\section{Conflicts of Interest}

The Authors have no conflicts of interest to declare regarding this study.

\section{Authors' Contributions}

CAR collected the initial data, reviewed the histological sections, and wrote the original draft. PTS obtained the permission of The Regional Ethical Review Board in Stockholm, revised the original draft, and introduced valuable suggestions.

\section{References}

1 Thompson EM, Price AB, Altman DG, Sowter C and Slavin G: Quantitation in inflammatory bowel disease using computerised interactive image analysis. J Clin Pathol 38(6): 631-638, 1985. PMID: 4008665. DOI: 10.1136/jcp.38.6.631

2 Allen DC, Hamilton PW, Watt PC and Biggart JD: Architectural morphometry in ulcerative colitis with dysplasia. Histopathology 12(6): 611-621, 1988. PMID: 3417243. DOI: 10.1111/j.13652559.1988.tb01985.x

3 Karstensen JG, Săftoiu A, Brynskov J, Hendel J, Ciocalteu A, Klausen P, Klausen TW, Riis LB and Vilmann P: Confocal laser endomicroscopy in ulcerative colitis: a longitudinal study of 
endomicroscopic changes and response to medical therapy (with videos). Gastrointest Endosc 84(2): 279-286.e1, 2016. PMID: 26945556. DOI: $10.1016 /$ j.gie.2016.01.069

4 Watanabe C, Sumioka M, Hiramoto T, Noda I, Oba S, Akagi M, Kitamoto $\mathrm{M}$, Yamada $\mathrm{H}$ and Imagawa $\mathrm{M}$ : Magnifying colonoscopy used to predict disease relapse in patients with quiescent ulcerative colitis. Inflamm Bowel Dis 15(11): 16631669, 2009. PMID: 19504617. DOI: 10.1002/ibd.20949

5 Rubio CA and Schmidt PT: Morphological classification of corrupted colonic crypts in ulcerative colitis. Anticancer Res 38(4): 2253-2259, 2018. PMID: 29599347. DOI: 10.21873/ anticanres.12469

6 Maeda Y, Kudo SE, Ogata N, Mori Y, Misawa M, Homma M, Nemoto T, Ogawa M, Sasanuma S, Sato Y, Kataoka S, Kouyama Y, Sakurai T, Igarashi K, Ogawa Y, Kato K, Ichimasa K, Nakamura H, Kudo T, Hayashi T, Wakamura K, Baba T, Inoue $\mathrm{H}$ and Ohtsuka $\mathrm{K}$ : Endocytoscopic intramucosal capillary network changes and crypt architecture abnormalities can predict relapse in patients with an ulcerative colitis Mayo endoscopic score of 1. Dig Endosc 32(7): 1082-1091, 2020. PMID: 32073691. DOI: $10.1111 /$ den. 13655

7 Morson BC: Rectal biopsy in inflammatory bowel disease. $\mathrm{N}$ Engl J Med 287(26): 1337-1339, 1972. PMID: 4564312. DOI: 10.1056/NEJM197212282872607

8 Cheng H, Bjerknes M, Amar J and Gardiner G: Crypt production in normal and diseased human colonic epithelium. Anat Rec 216(1): 44-48, 1986. PMID: 3094402. DOI: 10.1002/ar.1092160108

9 Seldenrijk CA, Morson BC, Meuwissen SG, Schipper NW, Lindeman $\mathrm{J}$ and Meijer CJ: Histopathological evaluation of colonic mucosal biopsy specimens in chronic inflammatory bowel disease: diagnostic implications. Gut 32(12): 1514-1520, 1991. PMID: 1773958. DOI: 10.1136/gut.32.12.1514

10 Washington K, Greenson JK, Montgomery E, Shyr Y, Crissinger KD, Polk DB, Barnard J and Lauwers GY: Histopathology of ulcerative colitis in initial rectal biopsy in children. Am J Surg Pathol 26(11): 1441-1449, 2002. PMID: 12409720. DOI: 10.1097/00000478-200211000-00006

11 Glickman JN, Bousvaros A, Farraye FA, Zholudev A, Friedman S, Wang HH, Leichtner AM and Odze RD: Pediatric patients with untreated ulcerative colitis may present initially with unusual morphologic findings. Am J Surg Pathol 28(2): 190-197, 2004. PMID: 15043308. DOI: 10.1097/00000478-200402000-00006

12 DeRoche TC, Xiao SY and Liu X: Histological evaluation in ulcerative colitis. Gastroenterol Rep (Oxf) 2(3): 178-192, 2014. PMID: 24942757. DOI: 10.1093/gastro/gou031

13 Gajendran M, Loganathan P, Jimenez G, Catinella AP, Ng N, Umapathy $\mathrm{C}$, Ziade $\mathrm{N}$ and Hashash JG: A comprehensive review and update on ulcerative colitis. Dis Mon 65(12): 100851, 2019. PMID: 30837080. DOI: 10.1016/j.disamonth.2019.02.004

14 Rubio CA, Johansson C and Kock Y: A quantitative method of estimating inflammation in the rectal mucosa. III. Chronic ulcerative colitis. Scand J Gastroenterol 17(8): 1083-1087, 1982. PMID: 7167739.

15 Rubio CA, Johansson C, Uribe A and Kock Y: A quantitative method of estimating inflammation in the rectal mucosa. IV. Ulcerative colitis in remission. Scand J Gastroenterol 19(4): 525530, 1984. PMID: 6463576.

16 Rubio CA: Corrupted colonic crypts bordering regenerating mucosal ulcers in ulcerative colitis. In Vivo 31(4): 669-671, 2017. PMID: 28652436. DOI: 10.21873/invivo.11110
17 Rubio CA and Schmidt PT: Asymmetric crypt fission in colectomy specimens in patients with ulcerative colitis. J Clin Pathol, 2020. PMID: 33328181. DOI: 10.1136/jclinpath-2020206694

18 Filipe MI: The mucous membrane of the normal human large intestine and the changes which occur in it immediately adjacent to proven carcinoma- A histochemical, autoradiographic and chemical study. PhD Thesis, University of London, 1971.

19 Levine DS and Haggitt RC: Normal histology of the colon. Am J Surg Pathol 13(11): 966-984, 1989. PMID: 2679155. DOI: 10.1097/00000478-198911000-00008

20 Rubio CA and Schmidt PT: Are non-dysplastic crypts with corrupted shapes the initial recordable histological event in the development of sporadic conventional adenomas? Anticancer Res 38(9): 5315-5320, 2018. PMID: 30194183. DOI: 10.21873/ anticanres. 12858

21 Goldstein NS and Ahmad E: Histology of the mucosa in sigmoid colon specimens with diverticular disease: observations for the interpretation of sigmoid colonoscopic biopsy specimens. Am J Clin Pathol 107(4): 438-444, 1997. PMID: 9124212. DOI: 10.1093/ajcp/107.4.438

22 Rubio CA and Kock Y: A digital quantitative method of estimating inflammation in the rectal mucosa. I. The normal limits in asymptomatic patients. Scand J Gastroenterol 16(6): 731-735, 1981. PMID: 6976614. DOI: 10.3109/00365528 109180997

23 Baker AM and Graham TA: Revealing human intestinal stem cell and crypt dynamics. Mol Cell Oncol 1(3): e970069, 2014. PMID: 27308359. DOI: 10.4161/23723548.2014.970069

24 Humphries A and Wright NA: Colonic crypt organization and tumorigenesis. Nat Rev Cancer 8(6): 415-424, 2008. PMID: 18480839. DOI: $10.1038 / \mathrm{nrc} 2392$

25 Rubio CA: Putative stem cells in mucosas of the esophagogastrointestinal tract. In: Stem cell, regenerative medicine and cancer. Singh SR (ed.). Nova Science Publishers Inc: New York, 10: 279-308, 2010.

26 Bjerknes M, Cheng H, Hay K and Gallinger S: APC mutation and the crypt cycle in murine and human intestine. Am J Pathol 150(3): 833-839, 1997. PMID: 9060821.

27 Wasan HS, Park HS, Liu KC, Mandir NK, Winnett A, Sasieni P, Bodmer WF, Goodlad RA and Wright NA: APC in the regulation of intestinal crypt fission. J Pathol 185(3): 246-255, 1998. PMID: 9771477. DOI: 10.1002/(SICI) 1096-9896(199807)185:3 $<246:$ :AID-PATH90>3.0.CO;2-8

28 Fauser JK, Donato RP, Woenig JA, Proctor SJ, Trotta AP, Grover PK, Howarth GS, Penttila IA and Cummins AG: Wnt blockade with dickkopf reduces intestinal crypt fission and intestinal growth in infant rats. J Pediatr Gastroenterol Nutr 55(1): 26-31, 2012. PMID: 22193181. DOI: 10.1097/MPG.0b013e318246b42d

29 Yu M, Wu P, Widelitz RB and Chuong CM: The morphogenesis of feathers. Nature 420(6913): 308-312, 2002. PMID: 12442169. DOI: 10.1038 /nature01196

30 Harris MP, Williamson S, Fallon JF, Meinhardt H and Prum RO: Molecular evidence for an activator-inhibitor mechanism in development of embryonic feather branching. Proc Natl Acad Sci USA 102(33): 11734-11739, 2005. PMID: 16087884. DOI: 10.1073/pnas.0500781102

31 Knasmüller S, Steinkellner H, Hirschl AM, Rabot S, Nobis EC and Kassie F: Impact of bacteria in dairy products and of the intestinal microflora on the genotoxic and carcinogenic effects 
of heterocyclic aromatic amines. Mutat Res 480-481: 129-138, 2001. PMID: 11506806. DOI: 10.1016/s0027-5107(01)00176-2

32 Ridlon JM, Wolf PG and Gaskins HR: Taurocholic acid metabolism by gut microbes and colon cancer. Gut Microbes 7(3): 201-215, 2016. PMID: 27003186. DOI: 10.1080/ 19490976.2016.1150414

33 Rubio CA and Schmidt PT: Severe defects in the macrophage barrier to gut microflora in inflammatory bowel disease and colon cancer. Anticancer Res 38(7): 3811-3815, 2018. PMID: 29970500. DOI: 10.21873/anticanres.12664

34 Chen R, Rabinovitch PS, Crispin DA, Emond MJ, Bronner MP and Brentnall TA: The initiation of colon cancer in a chronic inflammatory setting. Carcinogenesis 26(9): 1513-1519, 2005. PMID: 15860506. DOI: 10.1093/carcin/bgi106

35 Kamarádová K, Vošmiková H, Rozkošová K, Ryška A, Tachecí I and Laco J: Morphological, immunohistochemical and molecular features of inflammatory bowel disease associated colorectal carcinoma and associated mucosal lesions - Single institution experience. Pathol Res Pract 215(4): 730-737, 2019. PMID: 30679085. DOI: 10.1016/j.prp.2019.01.010
36 Levin B, Lennard-Jones J, Riddell RH, Sachar D and Winawer SJ: Surveillance of patients with chronic ulcerative colitis. WHO Collaborating Centre for the Prevention of Colorectal Cancer. Bull World Health Organ 69(1): 121-126, 1991. PMID: 1905205.

37 Lightner AL, Vogler S, McMichael J, Jia X, Regueiro M, Qazi $\mathrm{T}$ and Steele SR: Dysplastic progression to adenocarcinoma is equivalent in ulcerative colitis and Crohn's disease. J Crohns Colitis 15(1): 24-34, 2021. PMID: 32592468. DOI: 10.1093/ecco-jcc/jjaa133
Received March 10, 2021

Revised May 24, 2021

Accepted May 25, 2021 